\title{
Dispatch
}

\section{Advocates and Allies: The Succession of a Good Idea or What's in a Meme?}

CALI L. ANICHA

North Dakota State University, USA

CANAN BILEN-GREEN

North Dakota State University, USA

ANN BURNETT

North Dakota State University, USA

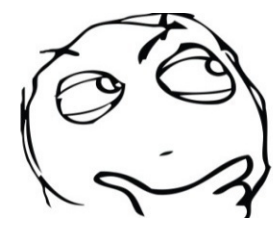

ABSTRACT In this two-part Dispatch we first trace the evolution of three interdependent terms - advocacy, allyship, and accountability - as a means to highlight their changing roles in driving impactful social justice efforts, then explore how this triad is manifested in a gender equity advocacy program fashioned at a Midwestern United States university, the Advocates and Allies (A\&A) initiative. In Part 1, we describe a memetic theory of culture to situate the findings of an Internet term search that reveals a mutable progression of meaning(s) for our threesome. This framework provides grounding for discussion in Part 2 of the wider social milieu reflected in the evolution of $A \& A$. We then offer an outline of central features of the initiative along with reflections from the field, and point out resources for learning more about how the program is being utilized. By surveying the succession of $A \& A$ within this culture-as-memetic context we intend to acknowledge what's been done by others whilst furthering the important and unfinished work of gender equity in academia. We close with interpretations and conclusions.

KEYWORDs equity; allyship; advocacy; accountability; culture; memetic

Correspondence Address: Cali L. Anicha, FORWARD Program, Office of the Vice Provost for Faculty Affairs and Equity, North Dakota State University, Fargo, ND USA; Email: c.mcdonaldmorken@ndsu.edu 
This two-part Dispatch is presented in response to the tsunami of domination culture reaching around the world in waves of increasingly blatant white nationalism, xenophobia, jingoism, misogyny, and disablism. Bitter manifestations of racialized, gendered, and enabled/ableist entitlements have become common daily occurrences from the schoolyard to the national stage. How might we who seek social justice navigate the storms of political and relational turmoil unleashed and repeatedly provoked by the current powersthat-be? How do we keep our heads up or down as the changing currents require, buoy ourselves up, and persist at the work of cultural transformation necessary to establish the more just and humane world we intend?

First, it is vital to examine our own beliefs about what constitutes justice and injustice. A clear and coherent grasp of what justice looks like is as crucial as a full and nuanced comprehension of the operations and influences of hegemony: the myriad social processes through which human beliefs and practices perpetuate injustice, re-instantiating domination through consent as much as through coercion (Lash, 2007). Our awareness of these two strands the justice we are determined to engender and the injustices we are currently enmeshed within - must operate in tandem, an approach that allows us to unmask the social practices that contribute to each.

To chart this course, in Part 1 What's in a Meme? we unpack what we have come to understand as an indispensable and interdependent social justice trifecta: advocacy, allyship, and accountability. We deliberately scrutinize accountability as a vital driver of social justice advocacy and allyship. In Part 2 Advocates and Allies we share details about the development of a program that applies this pivotal triad in the work of men faculty working for gender equity in academia. ${ }^{1}$ Following Part 2, we present interpretations and conclusions. This mini-series is offered in the hope that our theoretical exploration, paired with an exemplar, will support us all in continuing to establish a world in which justice flows, in the words of Martin Luther King, Jr. "down like water" and domination culture ebbs and finally disappears.

\section{Part 1: What's in a Meme?}

In this section we probe the cultural evolution of the interdependent concepts of advocacy, allyship, and accountability. We begin by briefly considering a theory of culture as memetic, then survey the history of the three concepts via cursory Internet term searches. The search results reveal swelling networks of the use of all three terms, as well as a shifting progression of meaning(s) for this potent triad, and thereby provide a view into the wider social contexts that underlie the origin and formation of the gender equity program described in Part 2.

\footnotetext{
${ }^{1}$ See https://www.ndsu.edu/forward/advocates_and_allies/
} 


\section{A Memetic Perspective on Culture}

Human cultures develop via networks of relationships and shared ideas; persistent ideas become cultural conventions guiding individual and group behavior and actions. When cultural knowhow is shared (Balkin, 1998) a meme operates as a "unit of cultural transmission," (Dawkins, 1989, p. 192) to leverage the inherent power of compelling ideas via social learning (Bandura, 2006; Marsden, 1998). Memes and genes are theorized to operate similarly: via repetitions or replication, variation or mutation, and fitness value or survival selection (Blackmore, 1999). Thus, when an idea-meme is shared, it is taken up by the mind(s) of other individuals, perhaps slightly altered, then remains in the "meme pool" if it demonstrates sufficient goodness of fit.

For example, over the past several decades analyses regarding what constitutes racism and antiracism have shifted from highlighting how people of color are oppressed through negative attributions purveyed via social institutions, to a focus on the underlying beliefs in white superiority that engender the unearned privileging of white people. The central recognition that the effects of racism are made possible through system-wide practices of racialized discrimination has remained. Approaches for identifying and addressing racial injustice have, however, changed. These analyses have been articulated within networks of people of color, then shared with networks of white people, and have emerged within various antiracism projects to guide interpersonal and institutional practices.

We believe that, although much of the information proliferating in today's digital age appears transient and inconsequential, some concepts become iterative cultural memes capable of wide influence precisely because they are meaningful and consequential. Such is the case with the three big ideas we find central to effective social justice efforts: advocacy, taking action in support of a cause; allyship, entering into relationships to pursue shared goals; and accountability to/with those with whom the advocacy and alliances are engaged, a perspective that includes concomitant expectations of responsibility for action on behalf of justice.

While academics tussle over definitions and measurement (Blackmore, 2010; McNamara, 2011; Situngkir, 2004), corporate groups and internet users are rapidly finessing the art of meme marketing (memevertizing) to share ideas in "clever, memorable, easily communicated and absurdly contagious" formats (Markowski, 2013, para. 5). Setting aside for the moment academic uncertainties, we adopt a memetic perspective as "a useful heuristic [for gaining] insight into the nature of the social world" (Marsden, 1998, Memetic Stance section, para. 1). It is from this angle that we investigate, via internet term searches, advocacy, allyship, and accountability as social justice memes. 
Advocacy, Allyship, Accountability: A Relatively Recent History

Advocacy and alliances are ideas with ancient roots in human cultures; but their social meanings and applications have shifted in response to changing values and politics. In today's global digitized information age, interactive explorations of social justice theory and praxis are yielding synergistic insights and practices. In many social justice-oriented organizations, advocacy and allyship have become nearly synonymous with accountability.

WWWS? What Would the Web Say?: Via term searches on the World Wide Web, we traced the histories of advocacy, allyship, and accountability. Limitations of this search include that only English language results are reported, thus the findings primarily reflect cultural views found in the United States, Canada, and the United Kingdom. Given that the Internet has been available to academia only since the 1980 s, and for commercial and personal use only since the 1990s, this account is necessarily a constrained chronology of the threesome. Even so, the number of search engine query "hits" summarized in Table 1 shows a memetic progression in the evolution of advocacy and allyship, with the attendant emergence of accountability as a vital partner (search completed July $22^{\text {nd }} 2016$ ). Results for a verbatim search for "advocates \& allies" included the institutions where A\&A (see Part 2) is being replicated. The advocates \& allies pairing was initially seen with LGBT + organizations and was also seen on sites addressing: a support community for nonprofit groups, a human rights' day event, homelessness, disability, support for public schooling, healthcare programs, youth engagement, mental health awareness, veganism, and domestic violence.

Overall, the results summarized in Table 1 show that in the 1980s advocacy links primarily reflected concerns regarding "vulnerable persons" along with legal, medical, and religious issues (48,200 hits). The 1990s showed similar foci with increasing mentions of human and civil rights associations with the term (450,000 hits). Calls for cross-cultural knowledge and respect emerged at the turn of the century $(25,000,000$ hits $)$, and explicit recognition of a need for collaboration with persons for whom the advocacy is meant began showing up post-2010 (58,400,000 hits for 2011-2016). 


\begin{tabular}{|c|c|c|c|}
\hline Search Terms & $\begin{array}{l}\text { Advocacy, } \\
\text { Advocate } \\
\text { (most results used } \\
\text { both terms) }\end{array}$ & Allyship & $\begin{array}{l}\text { Advocates and } \\
\text { Allies/A\&A }\end{array}$ \\
\hline Time Period & \multicolumn{3}{|c|}{ Total Results } \\
\hline $\begin{array}{l}\text { 1980’s } \\
1990 \text { 's } \\
2000-2010 \\
2011-2016\end{array}$ & $\begin{array}{l}48,200 \\
450,000 \\
25,000,000 \\
58,400,000\end{array}$ & $\begin{array}{l}1 \\
14 \\
983 \\
20,100\end{array}$ & $\begin{array}{l}1,110 \\
6,870 \\
102,000 \\
1,110,000\end{array}$ \\
\hline & \multicolumn{3}{|c|}{ Topical Results } \\
\hline 1980’s & $\begin{array}{l}\text { Legal, } \\
\text { medical/patients, } \\
\text { religious and } \\
\text { "vulnerable } \\
\text { persons" advocacy }\end{array}$ & $\begin{array}{l}\text { Single result } \\
\text { associated with Safe } \\
\text { Zone webpage at } \\
\text { Rutgers University, } \\
\text { "awareness and } \\
\text { allyship" training } \\
\text { noted to have begun } \\
\text { Feb. 15, } 1988\end{array}$ & $\begin{array}{l}\text { Business/labor, } \\
\text { military/defense, } \\
\text { political, } \\
\text { medical/health, } \\
\text { disability; mention } \\
\text { of national gay } \\
\text { rights organizing }\end{array}$ \\
\hline 1990’s & $\begin{array}{l}\text { Similar to previous } \\
\text { decade with } \\
\text { occasional } \\
\text { mentions of human } \\
\text { and civil rights - } \\
\text { Title IX and } \\
\text { disability/special } \\
\text { education }\end{array}$ & $\begin{array}{l}\text { Primarily LGBT; } \\
\text { also antiracism }+ \\
\text { some commentary } \\
\text { on accountability }\end{array}$ & $\begin{array}{l}\text { Business/industry, } \\
\text { political, health; } \\
\text { increasing } \\
\text { instances of anti- } \\
\text { violence and anti- } \\
\text { oppression, pro } \\
\text { diversity and } \\
\text { environment } \\
\text { citations }\end{array}$ \\
\hline $2000-2010$ & $\begin{array}{l}\text { Continue to see } \\
\text { medical, legal, } \\
\text { religious; add } \\
\text { consumer, housing } \\
\text { advocacy; state the } \\
\text { need for cross- } \\
\text { cultural knowledge, } \\
\text { respect }\end{array}$ & $\begin{array}{l}\text { LGBT, antiracism, } \\
\text { diversity, cultural } \\
\text { competence } \\
\text { do's/don'ts }\end{array}$ & $\begin{array}{l}\text { Using both terms } \\
\text { for legal and } \\
\text { issues-based } \\
\text { community } \\
\text { organizing: } \\
\text { environment, } \\
\text { LGBT, antiracism, } \\
\text { sexism, disability, } \\
\text { education, includes } \\
\text { accountability of } \\
\text { those with } \\
\text { power/advantage }\end{array}$ \\
\hline $\begin{array}{l}2011-2016 \\
\text { [denotes a } 5 \text { - rather } \\
\text { than } 10 \text {-year } \\
\text { span] }\end{array}$ & $\begin{array}{l}\text { Focus on skill- } \\
\text { building in } \\
\text { advocacy work; } \\
\text { explicit recognition } \\
\text { of need for } \\
\text { collaboration with } \\
\text { persons for whom } \\
\text { the advocacy is } \\
\text { meant }\end{array}$ & $\begin{array}{l}\text { Pitfalls and } \\
\text { commoditization of } \\
\text { allyship/ally } \\
\text { identities; despair of } \\
\text { marginalized folks } \\
\text { due to } \\
\text { ineffective/insincere } \\
\text { allyship/claims }\end{array}$ & $\begin{array}{l}\text { LGBT primarily } \\
\text { paired with } \\
\text { accountability for } \\
\text { education and } \\
\text { action; } \\
\text { FORWARD A\&A } \\
\text { and WEPAN; } \\
\text { homelessness, } \\
\text { disability self- } \\
\text { advocacy, tribal } \\
\text { sovereignty }\end{array}$ \\
\hline
\end{tabular}

Table 1. Internet History Term Search from 1980's through July 2016. (Note: The LGBT Advocate magazine began publishing in 1967.) 
Allyship followed a similar path, though with lower frequencies - from a fundamental awareness of the concept, to cultural competence within alliances. The single instance of allyship found in the 1980s was associated with an LGBT Safe Zone site; hits grew to 20,100 by mid-2016. Concerns regarding insincere and ineffective ally behaviors are found frequently in more recent posts; however, explicit mention of accountability emerged concomitantly on sites exploring allyship as early as the 1990s. In the 1980s and 1990s accountability primarily appeared in relation to business, military, political, and medical concerns, though the term was also seen in association with disability and gay rights. By 2000 accountability was firmly rooted in analyses of the responsibilities of persons with power/advantage regarding community activism for the environment, LGBT+ rights, antiracism, antisexism, and disability justice.

An exploration of the content found on the most recently developed sites revealed a prevailing community-based construal of accountability in which whites are understood to be accountable to/with people of color, men to/with women, straights to/with gender nonconforming individuals, and TABs (temporarily able-bodied) and neurotypicals accountable to/with people perceived as disabled, etc. Accountability to/with marginalized "others" is identified as crucial because clear understandings about the behaviors and systems that perpetuate social (in)justices rarely emerge spontaneously in the minds of privileged individuals. Rather, persons directly experiencing unearned disadvantages become cartographers of the privilege landscape. Unfortunately, and much to the detriment of us all, current dominant culture hegemony conspires with our tendencies to avoid uncertainty and discomfort, and thus operates to maintain the invisibility (to the privileged) of unearned advantaging. To be genuinely accountable, it is crucial to first seek out and listen to those with whom allyship is sought. In that listening, we must learn to recognize when in-group bias/superiority or stereotyping influences or interrupts accurate perceptions and understandings, and thereby perpetuates disconnection, judgment, and conflict. When advocates engage in deep listening and enter into allyship with a clear recognition that each one's liberation is equally at stake, then genuine accountability can be cultivated.

In sum, accountability is essential for and central to respectful, genuine, and beneficial advocacy and allyship. When it comes to the socially constructed and sanctioned unearned privileging of whiteness, maleness, gender-conformity, and physical- and neuro-typicality, those among us to whom privileges accrue are too often unaware and undereducated. Until those of us with unearned advantage hold ourselves accountable to/with persons experiencing unearned disadvantage, we cannot fully comprehend the injustices of the world, or hope to engender justice. 


\section{Part 2: NDSU FORWARD Advocates and Allies}

In Part 2 of this Dispatch, we investigate the memes of advocacy, allyship, and accountability in relation to the development of a gender equity program at a Midwestern United States university. We begin by recognizing that the Advocates and Allies program (A\&A) is founded on the important work accomplished by multiple sociopolitically marginalized communities who have developed and shared critical analyses and organizing tools for social justice. After recounting the succession of campus equity efforts that prefigured and provided crucial grounding for the program, we outline central features of the A\&A faculty gender equity initiative. Next, we share the responses of men faculty and administrators to their engagement in gender equity work.

\section{A Review of Campus Equity Efforts Circa 1980s to Present Day}

Academics are neither separate from nor immune to cultural contexts, and academia is a veritable bastion of unearned advantaging and privileging (Thomas, 2017). Thus, although critical studies of race, gender (cis and LGBT+), and disability are acknowledged as transdisciplinary academic fields, their knowledge-bases have necessarily been generated from marginalized communities. An honest review of the lineage and social evolution of the central tenets of any intellectual activism (Hill Collins, 2013) must acknowledge the legions of organizers and activists who have imbued advocacy and allyship with a rich critical cultural reserve that supports us all in the ongoing project of social equity. By examining the succession of this particular university-based program within the broadened social context detailed in Part 1, we wish to give appropriate recognition to communitybased activists, whilst furthering the important and unfinished work of gender-equity in academia.

In the late 1980s, and through the next two decades, the accountability meme came to life at our university through two primary grassroots sources. First, antiracist education and organizing workshops were hosted by local community organizations, often in collaboration with our university. Those trainings, provided by the People's Institute for Survival and Beyond, ${ }^{2}$ and Crossroads Antiracism and Organizing, ${ }^{3}$ were grounded in systemic power analyses and a recognition of the accountability of white people to/with communities of color in the work to undo racism. Although the initial focus of the workshops was an analysis of the myriad ways in which people of color experienced racism, an examination of the primary role(s) of

\footnotetext{
${ }^{2}$ See http://www.pisab.org

${ }^{3}$ See http://crossroadsantiracism.org
} 
government, schools, and religious organizations in perpetuating racial inequities followed. The take-home message was clear: those institutions were run by recipients of unearned privileging based on beliefs of white racial superiority, and racial equity would only be realized when white people understood and acted on this knowledge. This early antiracism work led to the development of TOCAR (Training Our Campuses Against Racism), a local multi-campus initiative that provided a continuum of introductory, intermediate, and advanced antiracism education and organizing activities until $2010 .^{4}$ Though our university-sanctioned antiracism team has been decommissioned, the lessons learned continue to inform the personal and professional lives of many campus and local community members.

Accountability is also reflected in the Safe Zone trainings that have been held continuously on our campus since 2001. ${ }^{5}$ Workshops offered through the current Safe Zone program have been adapted from community-based ally networks in support of lesbian, gay, bisexual, transgender, queer, questioning, intersex, asexual (LGBTQIA) communities. Similarly to antiracism work, Safe Zone programming is grounded in systemic power analyses; recognition of the accountability of straight people (cisgender hetero) to/with gendernonconforming communities is a central tenet.

It is probable that there were influential social justice efforts on our campus that preceded our time, though we have not researched that question. What we can say from our current perspective is that the antiracism analyses shared with us by community organizers, in which white people are guided to seek out, listen to, and act with people of color, has stayed with us. We also learned that this is often difficult medicine for white people to swallow in the face of a social system that constantly represents white experience not only as the superior, but as the sole norm. Similarly, Safe Zone trainings invite the cisgender heterosexual majority to recognize that their sexuality is presented as a sole and superior norm, and to accept accountability to/with gender nonconformists. Although the ongoing educational and advocacy efforts of the Safe Zone program have been crucial in promoting a welcoming campus climate, local and regional politics continue to be less than welcoming. Indeed, the recent rise in misogynistic rhetoric across the United States is allowing increases in gendered discrimination in all its forms (Khazan, 2016). Even so, our campus antiracism and Safe Zone efforts have borne fruit in the form of the A\&A model.

In 2008 the A\&A program began as a signature project of ADVANCE FORWARD, ${ }^{6}$ a National Science Foundation (NSF) funded gender equity initiative launched at our university. The program was distinctive in its focus on men faculty and offered an adaptable model for gender equity advocacy in academic workplaces (Anicha, Bilen-Green, Burnett, Froelich \& Holbrook, 2017; Anicha, Burnett \& Bilen-Green, 2015). Unique aspects included that

${ }^{4}$ See https://www.ndsu.edu/diversity/diversity_council_information/anti_racism_team/

${ }^{5}$ See https://www.ndsu.edu/safezone

${ }^{6}$ See https://www.ndsu.edu/forward/ 
A\&A was designed to address the gender equity education needs of men faculty while simultaneously leveraging their substantial social and university governance powers. To initiate the A\&A model, tenured men faculty who had demonstrated engagement in gender equity efforts were recruited to establish a core group of Advocates. The goal of the campus-wide program continues to be: (a) educate men faculty about gender inequity in academia; (b) introduce men faculty to strategies for bringing about positive change in their departments and colleges; and (c) build a supportive network of men Advocates and Allies to work to create a more equitable climate for women faculty.

Advocates are committed to increasing their understanding of gender bias and its impact on the academic careers of women. They educate themselves about issues of gender inequity, and they work to increase the number of women faculty, encourage the hiring and promotion of women faculty into administrative positions, and ensure the fair and equitable treatment of women within their institution. Advocates develop and offer regularly scheduled Ally workshops for men faculty who are interested in becoming Allies, and follow up with informal meetings to discuss case studies with the intent of continuing to increase their and the Allies knowledge about gender inequity in higher education.

Allies are men faculty who participate in gender equity (Ally) workshops and are expected to take action primarily within their departments including by speaking up at meetings, inviting women colleagues to collaborate on research, and serving on committees in place of their women colleagues to reduce the inequity in service loads. Allies can volunteer to become Advocates as they become more familiar with the program. A comparison of the A\&A program structures with equity approaches used in corporate spheres shows many similarities. ${ }^{7}$ However, the clarity with which A\&A affirms and acts on the need to access direct support and guidance from women appears to be unique.

Rather than expecting men faculty to be knowledgeable about gender inequities, a foundational assumption of A\&A is that all men, including highly educated academics, need multiple, iterative gender equity learning opportunities to become aware of the existing hegemony of noxious standards of what bell hooks has identified as patriarchal masculinity (2005). Men faculty who participate in A\&A accept responsibility for their own and other men faculty members' (re)education and commit to taking corrective steps to overcome the patriarchal norms that shape them. To sustain awareness and inform action, men faculty in the A\&A program consider inter/national, local, campus, and departmental data that reveal gendered inequities, and learn about the myriad ways implicit bias manifests in individual as well as institutional actions. Importantly, maintaining formal advisory relationships

${ }^{7}$ e.g., the National Center for Women and Information Technology comprehensive review of Top 10 Ways to Be a Male Advocate for Technical Women at

https://www.ncwit.org/resources/read-online-maleadvocate 
with women faculty provides pathways for accountability and promotes effective advocacy and allyship.

Both of the sustained campus equity efforts, TOCAR and Safe Zone, reviewed above adopted a community-based social justice construal of accountability with slight variations to suit university contexts. Several of the faculty members who developed the A\&A program had also participated in those efforts and were well-grounded in analyses of accountability made there. If the FORWARD A\&A insistence on women faculty as advisors is understood as an accountability meme variant, then it appears to have demonstrated fitness value and successfully negotiated selection pressures to date.

\section{What Do the Men Say? Notes from the Field}

Although the A\&A program was developed at our university expressly for men in academic settings, the approach is firmly rooted in the fundamentals of forming effective alliances for equity across sociopolitical differences. The effectiveness of the model relies on the approach being adopted by a stable network of Advocates. We have recently garnered a second NSF grant to more comprehensively support the development and test the fidelity of A\&A programs at other universities. ${ }^{8}$ Since the inception of the model in 2008 we have gathered evaluation data from workshop participants; and in 2013 an external evaluator interviewed 15 Advocates at our university to learn why they decided to join the initiative, what issues they hoped to address, and challenges they experienced. ${ }^{9}$ Over the past year, interviews have been completed with men who are coordinating A\&A programs on their commitment to accountability. Informational sessions about the A\&A model have been presented at a number of conferences, Advocates and Ally workshops have been held on 10campuses, and ethnographic notes describing attendees' reactions were collected during recent Advocate and Ally workshops. These data show that men faculty participate in the A\&A program for several reasons, the majority of which are internally motivated.

Reasons to participate include specific examples of inequities that were bothersome, distress about knowing that inequities exist, or simply a desire to be part of the solution to gender inequity. One Advocate recalled a faculty search in his department in which a woman candidate was on the short list: "I remember a couple of my senior colleagues saying, 'Well, looks like maybe she's been riding people's coat tails.' And you look at her record, and she had something like 50 publications and 35 first author publications. Like, how can you look at that and say that she's been riding coat tails?" Another Advocate remarked about the issues, " $\ldots$ in our engineering college, which

${ }^{8}$ See https://www.ndsu.edu/forward/advocates_and_allies/about_advocates_allies/

${ }^{9}$ All internal and external evaluations are located at www.ndsu.edu/forward 
has struggled horrendously with gender representation, particularly at the faculty level. Yeah, there's problems and anybody sees it."

Many respondents indicated that gender inequities observed for women family members had led them to desire to learn more and participate in gender equity efforts. One Advocate explained, "Because, you know, I have two sisters. So I know the difficulty, they talk at home." Others indicated that observing gendered discrimination or hearing information about gender disparities at their own university had led them to A\&A involvement. One Advocate noted that his department was "male-dominated" and after witnessing bias against women faculty, he wanted to "take steps to improve that and help more people understand the situation." A few of the participants felt they were well-positioned to influence change, including one department chair who said, "I also thought that our department was a good example, and I could lead from that because we went from a department of two women and eleven men to now being seven women and six men, and I'd like to think I had something to do with that."

What do men faculty get from participation in A\&A? Advocates reported that A\&A engagement provided them with opportunities to gain knowledge about social justice concerns and to take corrective actions; an ethnographic note taker reported, "participants highlight[ed] their commitment to diversity and gender equity/empowerment." One interviewee noted that being an Advocate "is as much a process of self-education as it is educating others, and so it's both an advocacy group but also a study group." On postworkshop surveys, A\&A participants reported that the workshop had substantially increased their awareness of gender inequities and had provided them with useful tools and strategies for addressing gender equity.

Comments included on evaluations frequently indicated that participants especially appreciated talking through anecdotal scenarios that both described gender discrimination taking place and provided appropriate and effective responses. Participants noted that having those conversations with other men was particularly beneficial. These data suggest that when men faculty are offered information, tools, and opportunities to work for gender equity, they are willing to do so. It may be that, when applied with critical analyses, using male workshop leaders and ensuring men-only dialogue is particularly wellsuited to disrupting patriarchal masculinity.

As is true for social justice efforts in general, push-back is to be expected when a real threat to the status quo is underway (Bishop, 2005).A recognition of the inevitability of such repercussions is one reason for recruiting tenured men faculty to act as Advocates. Nevertheless, even when protected by tenure, individual men acting on behalf of gender equity are likely to experience hostility and rejection from some of their colleagues; this is a concern in a workplace where collaborations and perceptions of collegiality can make or break a career. Thus, anticipation of backlash also underlies the rationale for the development of interactive campus-wide support networks of Advocates and Allies. Cohorts of men acting on behalf of gender equity may 
be less vulnerable to backlash; however, meaningful institutional change requires tactical, thorough, and sustained efforts, meaning that men need to commit to the long haul (Horton, Kohl \& Kohl, 1990) and be prepared to meet resistance with persistence and creativity.

\section{So - What's in a Meme? Interpretations and Conclusions}

Our cursory investigation of web content related to advocacy and allyship over the last 35 years indicates that the roles of advocates have morphed. Overall, the essence of advocacy has shifted from political, legal, and economic foci, to the use of social power on behalf of vulnerable others, to expectations that unearned social power can be deployed to dismantle systems of unearned advantaging. Similarly, the idea of allyship has shifted to express lateral rather than hierarchical "helping" relationships, and to expectations that allyship is an ongoing real-time behavior rather than a static identity.

The FORWARD A\&A program took up the social justice memes of advocacy, allyship, and accountability that were central to the existing community-driven antiracism and LGBTQ collaborations, and adapted them to advance gender equity in academia. Accountability was centralized via formal processes for listening to the input of and acting with women faculty. This is no small contribution given the positioning of academics as "knowledge creators." In the case of our institution, the community shared knowledge, ways of knowing, analyses, and lived experience with academics, and the academics translated those gifts into change processes for campus communities that had been hardwired to support privilege. Reviewing our university history alongside evolving perceptions of advocacy, allyship, and accountability reveals that A\&A is richly grounded in this social justice trifecta.

In sum, our concern is that fidelity to the core meme of accountability is not lost. Crucially, the gender-equity work of men must be grounded in a social justice construal of accountability lest it reflect no more than tired repetitions of unearned privilege. Whether operating in academic, corporate, political, or community settings, recognizing this essential tenet will improve the effectiveness and integrity of social justice efforts. As this brief review of the conceptual terrain of advocacy, allyship, and accountability has shown, these are evolving ideas. With each iteration we come closer to the desired outcomes of equity and justice. If this contemplation on social justice has resonated with you, consider yourself memed. May you go forth and multiply! 


\section{Acknowledgements}

This research in part was supported by National Science Foundation Grants \# HRD-0811239 and \# HRD-1500604.

\section{References}

Anicha, C. L., Bilen-Green, C., Burnett, A., Froelich, K., \& Holbrook, S. (2017). Institutional transformation: Toward a diversity-positive campus culture. Journal of Women \& Minorities in Science and Engineering, 23(2). doi: 10.1615/JWomenMinorScienEng.2017017021

Anicha, C. L., Burnett, A., \& Bilen-Green, C. (2015). Men faculty gender-equity advocates: A qualitative analysis of theory and praxis. Journal of Men's Studies, 23(1), 21-43.

Balkin, J. M. (1998). Cultural software: A theory of ideology. New Haven, CT: Yale Univeristy Press.

Bandura, A. (2006). Toward a psychology of human agency. Perspectives on Psychological Science, 1(2), 164-180.

Bishop, A. (2005). Beyond token change: Breaking the cycle of oppression in institutions. Halifax, N.S.: Fernwood.

Blackmore, S. (1999). The meme machine. New York: Oxford University Press.

Blackmore, S. (2010). Memetics does provide a useful way of understanding cultural evolution. In F. Ayala \& R. Arp (Eds.), Contemporary debates in philosophy of biology (pp. 255-272). Malden, MA: Wiley-Blackwell.

Dawkins, R. (1989). The selfish gene. Oxford: Oxford University Press.

Hill Collins, P. (2013). On intellectual activism. Philadelphia, PA: Temple University Press.

hooks, b. (2005). The will to change: Men, masculinity, and love. New York: Washington Square Press.

Horton, M., Kohl, J., \& Kohl, H. R. (1990). The long haul: An autobiography (1st ed.). New York: Doubleday.

Lash, S. (2007). Power after hegemony: Cultural studies in mutation? Theory Culture \& Society, 24(3), 55-78.

Markowski, J. (2013). The best examples of meme marketing. Sparks: Insights into content, marketing, $P R$, and results [Social media blog]. Retrieved from http://sparksheet.com/thebest-examples-of-meme-marketing/

Marsden, P. (1998). Memetics and social contagion: Two sides of the same coin? Journal of Memetics - Evolutionary Models of Information Transmission, 2(2), 171-185.

McNamara, A. (2011). Can we measure memes? Frontiers in Evolutionary Neuroscience, 3(1), $1-7$.

Situngkir, H. (2004). On selfish memes: Culture as complex adaptive system. Journal of Social Complexity, 2(1), 20-32. 